\title{
Mobile Phone in Stomach-Is Endoscopic Trial Worthwhile?: A Case Report
}

\author{
Ankush Pawar ${ }^{1}$ Ashok Dalal ${ }^{1} \quad$ Amol Dahale ${ }^{1}$ Sanjeev Sachdeva ${ }^{1}$ Amarender Singh Puri ${ }^{1}$
}

\author{
${ }^{1}$ Department of Gastroenterology, G.B. Pant Institute of \\ Postgraduate Medical Education and Research, New Delhi, India
}

Address for correspondence Ashok Dalal, MD, DM (Gastroenterology) G.B. Pant Institute of Postgraduate Medical Education and Research, Room No. 205, Academic Block, 1, Jawaharlal Nehru Marg, New Delhi 110001, India (e-mail: drashokdalal83@gmail.com).

\author{
Abstract \\ Keywords \\ - Endoscopy \\ - Foreign body ingestion \\ - Gastric foreign body
}

\begin{abstract}
A 35-year-old male prisoner with a history of mobile phone ingestion was refereed to our center for management. Clinical examination was unremarkable. After confirmation on abdominal X-ray, we removed it endoscopically without any complication. To the best of our knowledge, this is only the second case report of successful endoscopic removal of mobile phone.
\end{abstract}

\section{Introduction}

Gastrointestinal (GI) foreign bodies may result from intentional or unintentional ingestion. It is a relatively common emergency faced by endoscopists. Almost $80 \%$ of subgroup belongs to pediatric population and it is almost always unintentional. The most common groups among adults that intentionally ingested foreign bodies are psychiatric patients and prisoners. Often complex foreign bodies found in these groups of patients, especially in the latter group. Most (90\%) ingested foreign bodies pass without the need for intervention..$^{1,2}$ Endoscopic intervention is required in 10 to $20 \%$ of patients, and surgical intervention is required in less than $1 \%{ }^{3,4}$ Most of guidelines talk about common foreign bodies. ${ }^{3,5}$ Complex foreign bodies ingestions are mostly described in case reports. Approach to these cases is not standardized. Endoscopic removal is uncommonly attempted and rarely successful. Few case reports are there about removal of rare or complex foreign bodies. Here we discuss one of a rare case of mobile phone retrieved endoscopically, very safely and averting need of surgery. Till date, there are only three case reports on mobile phone ingestion as foreign body, out of which only one showed that it could be removed endoscopically. ${ }^{6-8}$

\section{Case}

A 35-year-old male prisoner was referred to our outpatient department with alleged history of ingestion of a mobile phone. An abdominal X-ray was done at the prison hospital which was showing a mobile phone in the stomach ( $\sim$ Fig. 1 ). Patient was hemodynamically stable and had no comorbidities.

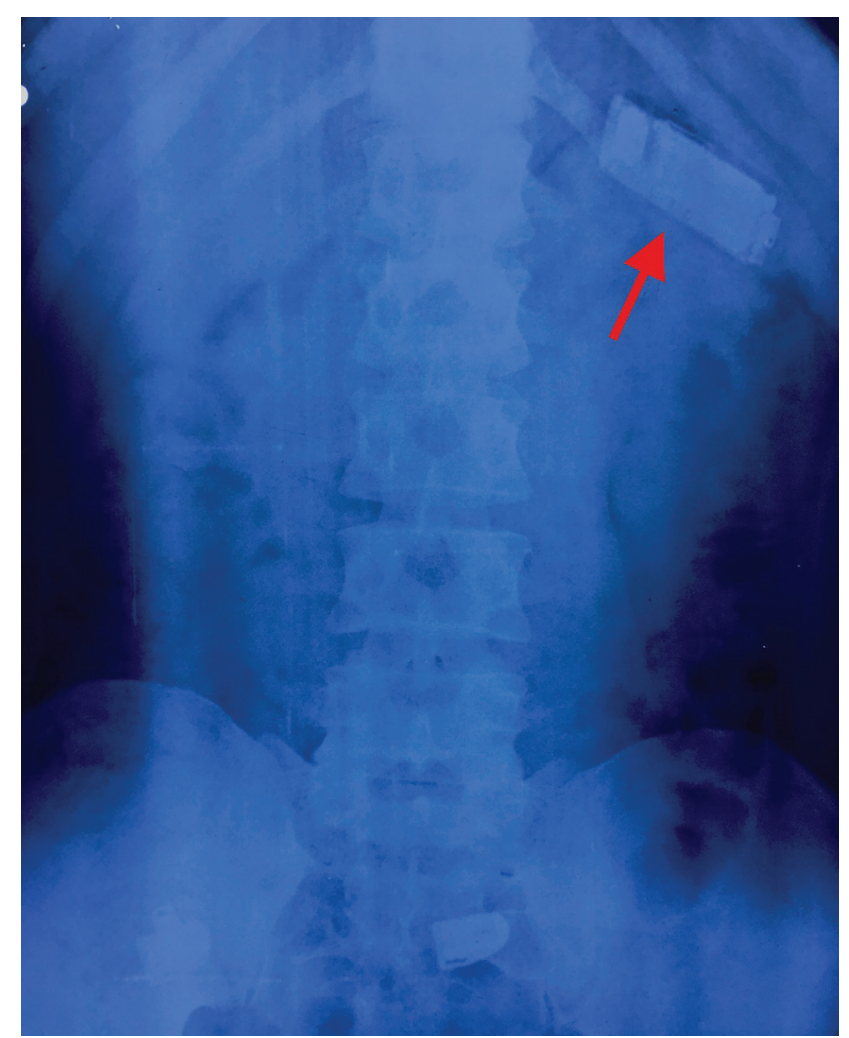

Fig. 1 X-ray abdomen showing the mobile phone (red arrow).

After obtaining consent, we did upper GI endoscopy. We found a mobile phone wrapped with polythene in stomach 

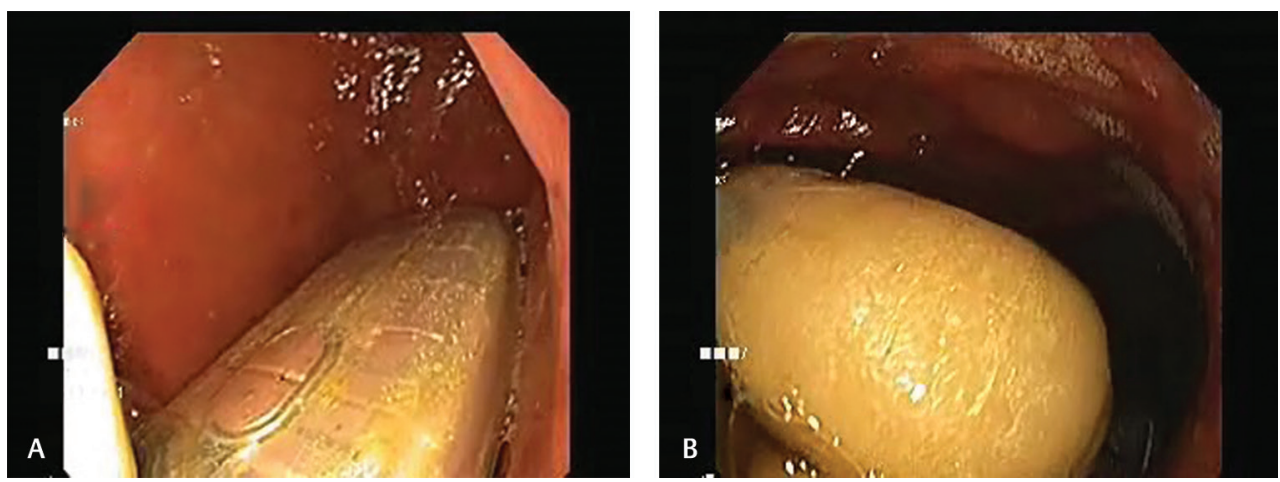

Fig. 2 Endoscopic images showing the mobile phone and drug packet in stomach.

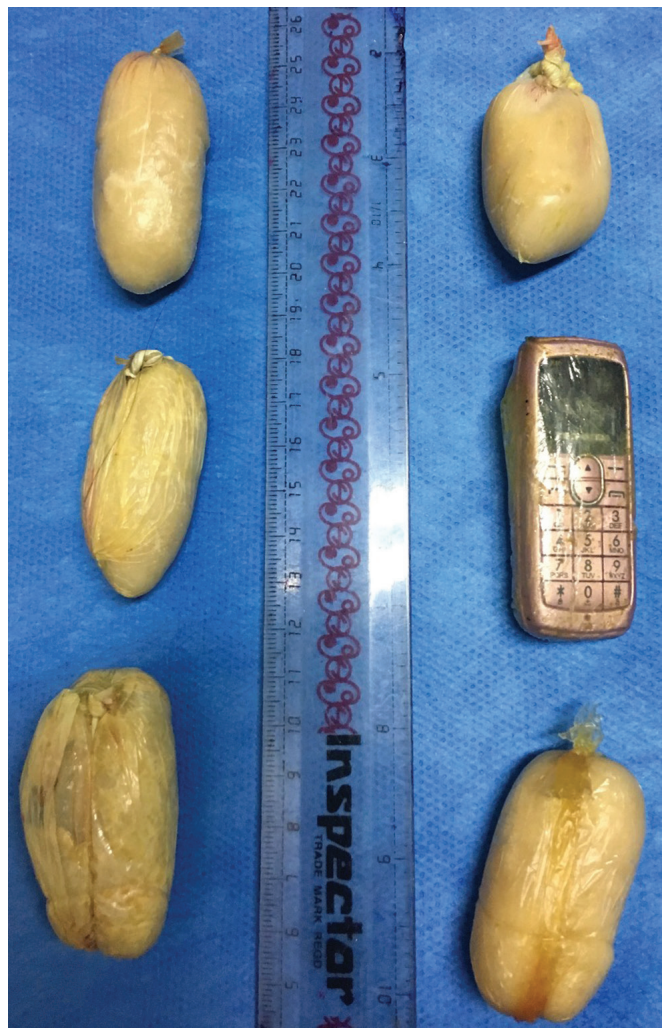

Fig. 3 Drugs packets and mobile phone after removal.

along (-Fig. 2) with five polythene wrapped pouches. With the help of snare, mobile phone was held tightly from the mouthpiece end so that the long axis comes parallel to the esophagus. While withdrawing at gastrointestinal endoscopy (GE) junction position was manipulated to align long axis of mobile phone with esophagus. This way phone was gently taken out without any resistance. We also removed all plastic pouches from stomach, one by one. After removal of all foreign bodies, we confirmed that there was no injury in upper GI tract. Postprocedure, patient was kept nil by mouth for 4 hours. After 4 hours, oral liquids were allowed. Patient was discharged from day care and referred back to the prison hospital. All the foreign bodies were handed over to the police personal accompanying the patient. He was followed-up 1 week later in outpatient department (OPD) and was completely asymptomatic.

\section{Discussion}

Although 80 to $90 \%$ foreign bodies spontaneously pass through GI tract without complications, 10 to $15 \%$ require endoscopic removal and less than $1 \%$ needs surgical intervention. Blunt objects more than $2.5 \mathrm{~cm}$ or long objects more than $5 \mathrm{~cm}$ are unlikely to pass beyond pylorus. ${ }^{9}$ Our case was a similar case scenario where a mobile phone $(6.5 \mathrm{~cm} \times 2.5 \mathrm{~cm}$; - Fig. 3) was found in stomach after 24 hours as expected. There is a scarcity of data on endoscopic removal of large blunt objects endoscopically. There are only three case reports published till date describing mobile phone as foreign body, two of which described the use of surgery as a definitive therapy. ${ }^{6,7}$ The other case report is the only one till now showing endoscopic removal of mobile phone. ${ }^{8}$ We used snare to remove mobile phone, using a technique where phone was removed along the long axis parallel to esophagus, so that there was no injury.

Our case is the second case report of successful endoscopic removal of mobile phone.

\section{Conclusion}

Though a single case report cannot make recommendations, but a message can be given to clinicians that endoscopic removal is a safe and can prevent surgery and worth an attempt before surgery.

\section{Funding}

No funding to declare.

\section{Ethical Approval}

An ethical approval was not required.

\section{Consent}

Written informed consent was obtained from patient for publication of this case report, a copy of which is available on request. 


\section{Conflict of Interest}

The authors have no conflicts of interest to declare.

\section{References}

1 Pellerin D, Fortier-Beaulieu M, Guegen J. The fate of swallowed foreign bodies: experience of 1250 instances of sub diaphragmatic foreign bodies in children. Prog Pediatr Radiol 1969;2:286:302

2 Carp L. Foreign bodies in the intestine. Ann Surg 1927;85 (4):575-591

3 Birk M, Bauerfeind P, Deprez PH, et al. Removal of foreign bodies in the upper gastrointestinal tract in adults: European Society of Gastrointestinal Endoscopy (ESGE) Clinical Guideline. Endoscopy 2016;48(5):489-496

4 Weiland ST, Schurr MJ. Conservative management of ingested foreign bodies. J Gastrointest Surg 2002;6(3):496-500
5 Ikenberry SO, Jue TL, Anderson MA, et al; ASGE Standards of Practice Committee. Management of ingested foreign bodies and food impactions. Gastrointest Endosc 2011;73(6):1085-1091

6 Obinwa O, Cooper D, O’Riordan JM. An ingested mobile phone in the stomach may not be amenable to safe endoscopic removal using current therapeutic devices: A case report. Int J Surg Case Rep 2016;22:86-89

7 Milivojevic V, Rankovic I, Milic L, Jeremic V, Jovanovic I. Mobile phone in the stomach: call the emergency endoscopist! Gastrointest Endosc 2017;86(1):233-234

8 Qureshi NA, Cherian N, Ben-Hamida A, Solkar MH. Endoscopic retrieval of an intentionally ingested mobile phone in an adult: first case report of its kind. Ann Clin Case Rep 2016;1:1172

9 Eisen GM, Baron TH, Dominitz JA, et al; American Society for Gastrointestinal Endoscopy. Guideline for the management of ingested foreign bodies. Gastrointest Endosc 2002;55(7):802-806 